Acknowledgements: This research was funded by a EULAR Health Professionals Research Grant

Disclosure of Interest: None declared

DOI: 10.1136/annrheumdis-2018-eular.3826

\section{SAT0718-HPR ARE THERE SYMPTOMS DISTINGUISHING FIBROMYALGIA FROM CHRONIC PAIN THAT ARE MISSING FROM THE 2016 CRITERIA?}

A.W. St John ${ }^{1}$, K.D. Jones ${ }^{2}$, R. Friend ${ }^{3}$, R.M. Bennett ${ }^{4} .{ }^{1}$ Department of Anesthesiology and Preoperative Medicine; ${ }^{2}$ Schools of Nursing and Medicine, Oregon Health and Science University, Portland; ${ }^{3}$ Department of Psychology, College of Arts and Sciences, Stony Brook University, Stony Brook, ${ }^{4}$ School of Nursing, Oregon Health and Science University, Portland, USA

Background: Fibromyalgia (FM) patients have a wide range of symptoms. Objectives: Herein we analysed 20 common symptoms to determine those that best discriminate between FM patients and chronic pain patients without FM (Chronic Pain).

Methods: 352 patients (mean age $50+/ 16.3$ years, $70 \%$ female) scheduled for a routine examination in two primary care practices were studied. 50 patients (14.2\%) had FM (based on 1990 ACR) and 108 patients (30.7\%) had Chronic Pain. All subjects completed a survey of 20 symptoms commonly found in $\mathrm{FM}$ patients - 10 were from the Symptom Impact Questionnaire (SIQR).

Results: Table 1 presents the 20 symptoms ranked by magnitude of Somers' D. This is a statistic that provides an estimate of predicting a diagnosis of fibromyalgia versus no fibromyalgia (OR: $1.87-8.00 ; p<0.001$ ). The top 10 symptoms showed strong correlations with diagnosis ( $D=0.49$ to 0.64 ) and large mean differences between the 2 groups (Means: 2.8-4.3). Notably, there was a 4.3 score difference in Persistent Deep Ache and only a 1.4 difference in SIQR Pain $(p<0.001)$. Using a 4-point criterion as a clinical cut-off $(0-10)$, symptoms best discriminating patients with FM from Chronic Pain were: Persistent Deep Aching $(86 \%$ vs. $36 \%$ ), Environmental Sensitivity ( $82 \%$ vs. $38 \%$ ), Poor Balance ( $82 \%$ vs. $35 \%)$, Tenderness to Touch ( $84 \%$ vs. $39 \%$ ) and Pain after exercise $(96 \%$ vs. $54 \%)$. The symptoms of Pain, Unrefreshing Sleep, Muscle Stiffness and Low Energy were high in both groups, thus they are not good discriminators.

Abstract SAT0718HPR - Table 1. Twenty common fibromyalgia symptoms ranked by Somers' D. The top 10 symptoms are shaded. SIQR symptoms are italicised.

\begin{tabular}{|l|c|c|c|c|}
\hline Symptom & $\begin{array}{c}\text { Somers'D } \\
\text { (rank) }\end{array}$ & $\begin{array}{c}\text { FM } \\
\text { Mean (\%) }\end{array}$ & $\begin{array}{c}\text { Chronic Pain } \\
\text { Mean (\%) }\end{array}$ & $\begin{array}{c}\text { Mean } \\
\text { difference }\end{array}$ \\
\hline Persistent Deep Aching & $.641(1)$ & $7.40(86)$ & $3.14(36)$ & 4.26 \\
\hline Intolerance to Noise & $.592(2)$ & $6.98(86)$ & $3.27(34)$ & 3.71 \\
\hline Environmental Sensitivity & $.574(3)$ & $6.82(82)$ & $3.04(38)$ & 3.78 \\
\hline Poor Balance & $.552(4)$ & $6.26(82)$ & $3.06(35)$ & 3.20 \\
\hline Pain after Exercise & $.534(5)$ & $8.08(96)$ & $4.07(54)$ & 4.01 \\
\hline Muscle Weakness & $.524(6)$ & $6.92(88)$ & $3.77(42)$ & 3.15 \\
\hline Tenderness to Touch & $.511(7)$ & $6.82(84)$ & $3.61(39)$ & 3.21 \\
\hline Muscle Stiffness & $.505(8)$ & $7.68(94)$ & $4.86(57)$ & 2.82 \\
\hline Intolerance to Bright Lights & $.492(9)$ & $6.58(72)$ & $3.41(33)$ & 3.17 \\
\hline Tender Muscles & $.491(10)$ & $7.90(94)$ & $4.94(56)$ & 2.96 \\
\hline Non-refreshing Sleep & $.452(11)$ & $7.54(84)$ & $4.60(52)$ & 2.94 \\
\hline Poor Memory & $.421(12)$ & $5.66(66)$ & $3.03(37)$ & 2.63 \\
\hline Intolerance to Cold & $.414(13)$ & $6.62(74)$ & $3.82(40)$ & 2.80 \\
\hline Irritable Bowel Symptoms & $.412(14)$ & $5.68(64)$ & $3.05(31)$ & 2.63 \\
\hline Swollen Joints & $.409(15)$ & $6.16(76)$ & $3.78(41)$ & 2.39 \\
\hline Depression & $.398(16)$ & $5.44(64)$ & $3.17(42)$ & 2.27 \\
\hline Stiffness & $.396(17)$ & $6.92(88)$ & $4.54(53)$ & 2.38 \\
\hline Chronic Headaches & $.390(18)$ & $5.62(66)$ & $3.45(38)$ & 2.17 \\
\hline Low Energy & $.349(19)$ & $6.82(84)$ & $4.92(61)$ & 1.90 \\
\hline Pain Level & $.320(20)$ & $6.54(94)$ & $5.12(69)$ & 1.42 \\
\hline
\end{tabular}

Conclusions: In this sample from 2 primary care practices, Persistent Deep Aching, Tenderness to Touch, Environmental Sensitivity, Poor Balance and Pain after Exercise were the best discriminators between FM patients and patients with Chronic Pain. Notably: Depression, Headaches, Poor Memory and Irritable Bowel symptoms were weak discriminators; in fact, none of the top 10 discriminators appear in the 2016 Fibromyalgia Diagnostic Criteria.

Disclosure of Interest: None declared

DOI: 10.1136/annrheumdis-2018-eular.5741

\section{SAT0719-HPR PERFORMANCE-BASED PHYSICAL FUNCTION MEASURE WAS MORE SENSITIVE TO DETECT RESPONDERS THAN SELF-REPORTED MEASURE AFTER A PHYSICAL THERAPY EXERCISE INTERVENTION IN PATIENTS WITH AXIAL SPONDYLOARTHRITIS}

C. Fongen $^{1}$, S.H. Sveaas ${ }^{1}$, A. Bilberg ${ }^{2}$, E. Pedersen ${ }^{3}$, M.W. Johansen ${ }^{4}$, S. van Weely ${ }^{5}$, K.B. Hagen ${ }^{1}$, H. Dagfinrud". ' Diakonhjemmet Hospital, Oslo, Norway; ${ }^{2}$ Sahlgrenska University Hospital, Gothenburg, Sweden; ${ }^{3}$ University Hospital of North Norway, Tromsø; ${ }^{4}$ Martina Hansen Hospital, Bærum, Norway; ${ }^{5}$ Leiden University Medical Center, Leiden, Netherlands

Background: Physical function is regarded as an important outcome in axia spondyloarthritis (axSpA) and the self-reported questionnaire Bath Ankylosing Spondylitis Functional Index (BASFI) is recommended for the evaluation. However, it is shown that BASFI may not be sufficiently sensitive to detect changes after physical therapy. Based on BASFI a disease-specific performance-based measure has been developed; the Ankylosing Spondylitis Performance-based Improvement (ASPI).

Objectives: To compare the proportion of patients with axSpA considered as responders in the performance-based function measure ASPI and the self-reported BASFI after a physical therapy exercise intervention.

Methods: This study was part of the ESpA-study (Exercise for SpondyloArthritis) which examines the effect of 12 weeks, supervised high intensity exercise intervention. Patients with axSpA were included from 4 centres in Scandinavia. Physical function was assessed with ASPI and BASFI at baseline and after 3 months. The ASAS20 response criteria were used to categorise patients as intra-individual responders or non-responders. In BASFI, patients were classified as responders if they showed an improvement of $\geq 20 \%$ and $\geq 1$ unit. In ASPI, patients were classified as responders if they showed an improvement of $\geq 20 \%$ on 1 or more subtest(s) and the absence of deterioration on the potential remaining test. Deterioration was defined as a worsening of $\geq 20 \%$ in 1 or more subtest(s). The proportion of patients categorised as intra-individual (non-) responders was examined with Chi square test.

Results: A total of 58 patients (intervention $n=30$, control $n=28$ ) with complete data on ASPI and BASFI were included in the analyses, $41 \%$ were male, mean age (SD) was 45 (10.7) years, 55\% had radiographic axSpA and mean disease activity (ASDAS) (SD) was $2.6(0.7)$. In BASFI, a score of $<1$ was present in $14 \%$ at baseline and in $22 \%$ at 3 months, indicating a ceiling effect (figure). The proportion of responders in the total group was $53 \%$ in ASPI and $36 \%$ in BASFI, $p=0.13$ (table 1). In the intervention group, $70 \%$ were responders in ASPI and $43 \%$ were responders in BASFI, $\mathrm{p}=0.02$.

Table. Number of responders measured with performance-based function test (ASPI) and self-reported physical function (BASFI) according to study sub-group

\begin{tabular}{lcccc}
\hline & $\begin{array}{c}\text { All patients } \\
(\mathrm{n}=58)\end{array}$ & $\begin{array}{c}\text { Intervention } \\
(\mathrm{n}=30)\end{array}$ & $\begin{array}{c}\text { Control } \\
(\mathrm{n}=28)\end{array}$ \\
\hline ASPI & Responder & $31(53 \%)$ & $21(70 \%)$ & $10(36 \%)$ \\
\hline \multirow{3}{*}{ BASFI } & $\begin{array}{c}\text { Non- } \\
\text { responder }\end{array}$ & $27(47 \%)$ & $9(30 \%)$ & $18(64 \%)$ \\
& $\begin{array}{c}\text { Responder } \\
\text { Non- } \\
\text { responder }\end{array}$ & $21(36 \%)$ & $13(43 \%)$ & $8(29 \%)$ \\
p-value* $^{*}$ & $37(64 \%)$ & $17(57 \%)$ & $20(71 \%)$ \\
\hline
\end{tabular}

Values are number (percentages). ${ }^{\star}$ Chi square test between (non-) responder in ASPI and BASFI within groups
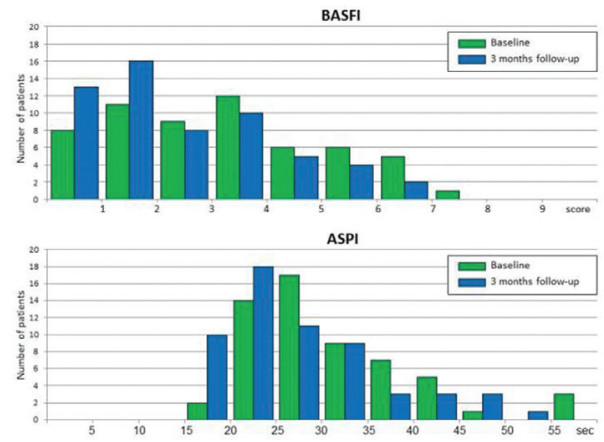

Abstract SAT0719HPR - Figure 1. Distribution of BASFI scores and time in seconds in ASPI assessed at baseline and at 3 months follow-up $(n=58)$. Lower values indicates better physical function in both measures 